\title{
Response to letter "The impact of scleral buckling technique application in diminishing high myopia"
}

\section{Xuran Dong ${ }^{1} \cdot$ Jing Liu ${ }^{1} \cdot$ Juan $\mathrm{Bu}^{1}$}

Received: 6 May 2020 / Revised: 6 May 2020 / Accepted: 8 May 2020 / Published online: 4 June 2020

(C) Springer-Verlag GmbH Germany, part of Springer Nature 2020

\section{Dear Editor,}

Thank you for the invitation. I read with interest about the letter entitled "The impact of scleral buckling technique application in diminishing high myopia" by Theodossiadis et al. Treatments for high myopia with macular retinoschisis or with retinal detachment have always been troublesome. In their studies they performed scleral buckling procedure in 25 myopic eyes with retinal detachment due to macular hole, demonstrating significant decrease of high myopia [1]. A silicone sponge of $7.5-\mathrm{mm}$ width was stretched and fixed at both ends to the sclera. It is an effective way to control retinal detachment and diminish high myopia at the same time. The authors also suggested that radial sponge position and suturing could obliterate pre-existing staphyloma, block future development, and prevent thinning of the posterior pole. The findings and suggestions are thought provoking and interesting.
As shown on the figure however, we find the silicon sponge quite close to the optic nerve. There may be a possible influence on the optic nerve or the surrounding tissue of the nerve. The operation can be quite complicated and likely demands mature surgical skills. Patients scheduled for this surgery would need to meet more strict indications.

\section{Reference}

1. Theodossiadis GP, Damanakis AG, Koutsandrea CN (1986) Diminution of myopia following operation of macular hole-induced retinal detachment. Klin Monbl Augenheilkd 189:289-292

Publisher's note Springer Nature remains neutral with regard to jurisdictional claims in published maps and institutional affiliations.

Juan $\mathrm{Bu}$

bujuan110@163.com

1 Department of Ophthalmology, Peking University Third Hospital, 49 North Garden Road, Haidian District, Beijing 100191, People's

Republic of China 